\title{
Analysis of the influence of respiratory disorders observed in preoperative spirometry on the dynamics of early inflammatory response in patients undergoing isolated coronary artery bypass grafting
}

\author{
This article was published in the following Dove Press journal: \\ Clinical Interventions in Aging \\ 14 July 2017 \\ Number of times this article has been viewed
}

\author{
Aleksandra Szylińska' \\ Mariusz J Listewnik ${ }^{2}$ \\ Iwona Rotter' \\ Aleksandra Rył ${ }^{3}$ \\ Andrzej Biskupski ${ }^{2}$ \\ Mirosław Brykczyński \\ 'Department of Medical \\ Rehabilitation, ${ }^{2}$ Department of \\ Cardiac Surgery, ${ }^{3}$ Department of \\ Histology and Developmental Biology, \\ Pomeranian Medical University, \\ Szczecin, Poland
}

Background: Preoperative spirometry provides measurable information about the occurrence of respiratory disorders. The aim of this study was to assess the association between preoperative spirometry abnormalities and the intensification of early inflammatory responses in patients following coronary artery bypass graft in extracorporeal circulation.

Material and methods: The study involved 810 patients (625 men and 185 women) aged $65.4 \pm 7.9$ years who were awaiting isolated coronary artery bypass surgery. On the basis of spirometry performed on the day of admittance to the hospital, the patients were divided into three groups. Patients without respiratory problems constituted $78.8 \%$ of the entire group. Restricted breathing was revealed by spirometry in $14.9 \%$ and obstructive breathing in $6.3 \%$ of patients.

Results: Inter-group analysis showed statistically significant differences in C-reactive protein (CRP) between patients with restrictive spirometry abnormalities and patients without any pulmonary dysfunction. CRP concentrations differed before surgery $(P=0.006)$ and on the second $(P<0.001)$, fourth $(P=0.005)$ and sixth days after surgery $(P=0.029)$. There was a negative correlation between CRP levels and $\mathrm{FEV}_{1}$.

Conclusion: In our study, the most common pulmonary disorders in the coronary artery bypass graft patients were restrictive. Patients with abnormal spirometry results from restrictive respiratory disorders have an elevated level of generalized inflammatory response both before and after the isolated coronary artery bypass surgery. Therefore, this group of patients should be given special postoperative monitoring and, in particular, intensive respiratory rehabilitation immediately after reconstitution.

Keywords: pulmonary function, C-reactive protein, cardiac surgery

\section{Introduction}

Among 1 million cardiac surgeries performed in the world each year, the most common is coronary artery bypass graft (CABG) surgery. The prognosis of patient survival in cardiac surgeries is the result of many factors, such as indications for surgery and its scope, age and sex of the patient, and the severity of the disease. The type of surgery, experience of the surgical team, and the choice of anesthesia method may also play an important role. ${ }^{1-7}$ In Europe, cardiovascular risk is most often assessed on the Euroscore scale. With regard to the respiratory system, this scale takes into account only chronic obstructive pulmonary diseases, defined as a "permanent intake of bronchodilators and/or steroids". The risk associated with this condition is estimated
Correspondence: Aleksandra Szylińska Department of Medical Rehabilitation, Pomeranian Medical University, 54, Żołnierska Street, 7I-2I0 Szczecin, Poland

Tel +48 9l 4800 9l4

Email aleksandra.szylinska@pum.edu.pl 
at $0.8 \%$. Measurable information about the degree of respiratory distress is provided by spirometry, which may also show an increased risk of postoperative complications. ${ }^{8}$ Available literature does not describe the relationship between reduced vital capacity and the degree of inflammatory response. Reports concern only healthy subjects. ${ }^{9-16}$ The increased rates of generalized inflammatory response may have many causes, including respiratory ones, such as primary lung disease and damage caused by infection or other external factors, or extracorporeal circulation. ${ }^{15,17-19}$ Respiratory performance may also be reduced as a result of cardiovascular disease. ${ }^{15,20}$

The aim of this research was the evaluation of the relationship between preoperative respiratory dysfunction and increased inflammatory response in patients after coronary artery bypass surgery in extracorporeal circulation.

Detailed analysis of preoperative spirometry may be helpful in qualifying patients for surgery and predicting respiratory complications following $\mathrm{CABG}$.

\section{Material and methods}

\section{Study population and exclusion criteria}

The study involved 1,169 patients with coronary artery disease admitted for CABG surgery at the Department of Cardiac Surgery, Szczecin, Poland, between January 2013 and December 2014. Out of these, 359 (30.7\%) patients with angina at rest (class IV in the Canadian Cardiovascular Score, $[\mathrm{CCS}]$ ) and those with acute myocardial infarction were excluded from the study. Subsequent analysis involved 810 (625 men and 185 women) aged $65.4 \pm 7.9$ years. On the day of admission, spirometry tests were performed using an AsSPIRO D200 v.101. (ASPEL S.A., Zabierzów, Poland). The measurements were performed according to the recommendations of the American Thoracic Society and the European Respiratory Society. ${ }^{21-24}$ All the patients provided written informed consent. The study was performed in accordance with the Declaration of Helsinki and approved by the Bioethics Committee of Pomeranian Medical University in Szczecin (KB-0012/121/14).

All the patients were interviewed for underlying diseases and concurrent symptoms. Symptoms were assessed using the CCS. In addition, information was gathered about concurrent and previous illnesses: diabetes mellitus, myocardial infarction, hypertension, renal disease, neoplasms, and neurological diseases. Blood pressure, body mass and height were measured. C-reactive protein (CRP) levels were assessed prior to surgery and on the second, fourth, sixth and eighth days after surgery.
All the patients had an isolated CABG with a sternotomy. The patients underwent standard postoperative management. Mechanical respiration was disconnected as quickly as possible. Rehabilitation proceedings were started in the preoperative period with clarification of the improvement methods. Positioning instruction was provided and training was provided for the assessment and prevention of postoperative pain in accordance with the "Painless Hospital" standards. Rehabilitation and education continued after the surgery in the intensive care unit and continued until the patients were discharged.

\section{Spirometry data}

The spirometry test included the following parameters: $\mathrm{FVC}$ and $\mathrm{FEV}_{1}, \mathrm{FEV}_{1} / \mathrm{FVC}$, and peak expiratory flow (PEF). According to the recommendations of the Global Initiative for Chronic Obstructive Lung Disease, $\mathrm{FEV}_{1} / \mathrm{FVC}$ values $<0.7$ at $\mathrm{FEV}_{1}<50 \%$ indicate acute respiratory obstruction, $\mathrm{FEV}_{1}$ between $50 \%$ and $80 \%$ indicates moderate obstruction, and above $80 \%$ indicates mild obstruction. Restrictive respiratory disorders were recognized when FVC was $<80 \%$, while normal lung function was defined as $\mathrm{FEV}_{1} / \mathrm{FVC} \geq 0.70$ and FVC $\geq 80 \%$. ${ }^{25}$ The patients were divided into three groups according to the spirometry score. The first group consisted of patients with normal lung function. The next two groups consisted of patients with respiratory disorders. The second group included patients with obstructive pulmonary disorders, and the third group comprised those with restrictive pulmonary disorders.

\section{Statistical analysis}

Statistical analysis was conducted using licensed Statistica 12 software (StatSoft, Inc., Tulsa, OK, USA). The descriptive statistics mainly used mean and standard deviations. The normality of distribution was checked using a Shapiro-Wilk test. The uniformity of variance was assessed using a Levene test. Data analysis for two groups was performed using a Student's $t$-test or Mann-Whitney $U$-test, while for three groups, analysis of variance or Kruskal-Wallis tests were used. Tukey's post-hoc test was used to evaluate the differences between the groups. Friedman's test was used to evaluate the variables before and after surgery. For the noncontinuous variables, the $X^{2}$-test was used. Correlations between spirometry parameters and CRP levels for quantitative data were evaluated using the Pearson's correlation coefficient, and the Spearman's rank correlation coefficient for qualitative variables. The significance level was set at $P \leq 0.05$. 


\section{Results}

Of the 810 patients, no respiratory system disorders were observed in 638 (78.8\%), while obstructive disorders were found in $51(6.3 \%)$ and restrictive in 121 patients (14.9\%). A total of $172(21.2 \%)$ patients reported abnormalities in spirometry. Patients without respiratory distress exhibited better cardiovascular performance shown by significantly higher mean ejection fraction (EF) than the other patients $(P=0.003)$. Patients with respiratory disorders had higher mean CRP before surgery $(P=0.012)$, and on the second $(P<0.001)$, fourth $(P=0.001)$ and sixth days after surgery $(P=0.009)$. Also, on the eighth day after surgery, CRP level was higher in patients with respiratory disorders compared with those without respiratory disorders, but the differences were not statistically significant $(P=0.57)$. Among patients with respiratory disorders, $72(41.86 \%)$ were being treated for diabetes, while in the group with normal respiratory parameters, 204 (31.97\%) patients were being treated. Differences were statistically significant $(P=0.015)$.

Anthropometric and epidemiological data were analyzed in the three groups. The results are summarized in Table 1.

Then, the differences between the groups were compared by means of a post-hoc test. Detailed analysis showed a significantly higher body mass index (BMI) in patients with restriction compared with the control group $(P=0.018)$ and patients with obstruction $(P=0.005)$. The lower EF was also shown in patients with restriction compared with patients with normal lung function $(P=0.003)$. Significant differences in CRP levels existed between patients with restrictive spirometry abnormalities and patients without any respiratory problems. The differences occurred before surgery $(P=0.006)$ and on the second $(P<0.001)$, fourth $(P=0.005)$ and sixth day after surgery $(P=0.029)$. Patients with obstructive pulmonary disease only showed significantly higher CRP levels, than patients without disturbances, on the fourth day after surgery $(P=0.049)$.

Multivariate analysis of the analyzed parameters showed statistically significant differences in age, respiratory dysfunction and CRP levels on the sixth day after surgery $(P=0.024)$. Another statistically significant difference was found for sex, respiratory disorders and CRP levels before surgery $(P=0.001)$.

Due to the observed significant differences in patients without disorders and with dysfunction of the respiratory system, CRP concentrations were assessed against other parameters assessed in patients. Table 2 summarizes the preoperative CRP levels and levels on the second, the fourth and the sixth day after surgery.

Table I Analysis of variance of differences in mean values of the studied parameters, in patients without disturbances in respiratory function and those with obstructive and restrictive respiratory disorders

\begin{tabular}{|c|c|c|c|c|}
\hline & \multicolumn{3}{|l|}{ Respiratory system } & \multirow[t]{2}{*}{$P$-value } \\
\hline & No disorders $(n=638)$ & Obstructive $(n=51)$ & Restrictive $(n=|2|)$ & \\
\hline Age, years & $65.17 \pm 7.91$ & $67.27 \pm 7.10$ & $65.64 \pm 8.32$ & 0.174 \\
\hline \multicolumn{5}{|l|}{ Sex } \\
\hline Female & $139(21.79 \%)$ & 16 (31.37\%) & 30 (24.79\%) & $0.25 I$ \\
\hline Male & 499 (78.21\%) & 35 (68.63\%) & 91 (75.2।\%) & \\
\hline BMI & $29.10 \pm 4.20$ & $28.07 \pm 5.70$ & $30.14 \pm 4.98$ & $0.01 \mathrm{I}$ \\
\hline ESL & $4.26 \pm 5.28$ & $5.94 \pm 5.58$ & $4.54 \pm 3.70$ & 0.237 \\
\hline $\mathrm{EF} \%$ & $49.21 \pm 9.97$ & $47.25 \pm 11.02$ & $46.31 \pm 10.01$ & 0.009 \\
\hline Current smoking & $216(48.00 \%)$ & $23(54.76 \%)$ & $60(58.82 \%)$ & 0.119 \\
\hline Years of smoking & $32.88 \pm 10.35$ & $35.47 \pm 11.67$ & $35.74 \pm 11.69$ & 0.157 \\
\hline Hypertonia arterialis & 480 (75.24\%) & 39 (76.47\%) & 97 (80.17\%) & 0.506 \\
\hline Diabetes mellitus & 204 (31.97\%) & $22(43.14 \%)$ & $50(4 \mid .32 \%)$ & 0.051 \\
\hline Renal failure & $27(4.23 \%)$ & $0(0 \%)$ & $8(6.61 \%)$ & 0.146 \\
\hline Myocardial infarction & 338 (52.98\%) & 27 (52.94\%) & $63(52.07 \%)$ & 0.983 \\
\hline \multicolumn{5}{|l|}{ CRP (mg/L) } \\
\hline Admission & $4.04 \pm 8.19$ & $4.86 \pm 5.81$ & $6.53 \pm 13.90$ & 0.023 \\
\hline 2 days after surgery & $66.89 \pm 30.23$ & $74.52 \pm 41.58$ & $78.5 I \pm 38.48$ & $<0.001$ \\
\hline 4 days after surgery & $199.78 \pm 77.48$ & $221.99 \pm 75.67$ & $221.42 \pm 78.86$ & 0.005 \\
\hline 6 days after surgery & $123.02 \pm 74.33$ & $141.19 \pm 72.40$ & $|4| .28 \pm 86.74$ & 0.034 \\
\hline 8 days after surgery & 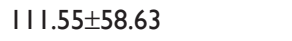 & | | $9.37 \pm 39.51$ & $123.06 \pm 94.59$ & 0.631 \\
\hline Hospital death & $8(1.25 \%)$ & $2(3.92 \%)$ & I (0.83\%) & 0.245 \\
\hline
\end{tabular}

Notes: Data in bold indicates statistical significance. Data presented as mean \pm standard deviation or $\mathrm{n}(\%)$.

Abbreviations: BMI, body mass index; ESL, Euroscore Logistic; EF, ejection fraction; CRP, C-reactive protein. 
Table 2 Descriptive statistics of preoperative CRP and mean postoperative CRP in study subjects

\begin{tabular}{|c|c|c|c|c|c|c|c|c|}
\hline & $\begin{array}{l}\text { CRP (mg/L) } \\
\text { before surgery }\end{array}$ & P-value & $\begin{array}{l}\text { CRP }(\mathrm{mg} / \mathrm{L}) 2 \\
\text { days after surgery }\end{array}$ & $P$-value & $\begin{array}{l}\text { CRP }(\mathrm{mg} / \mathrm{L}) 4 \\
\text { days after surgery }\end{array}$ & $P$-value & $\begin{array}{l}\text { CRP }(\mathrm{mg} / \mathrm{L}) 6 \\
\text { days after surgery }\end{array}$ & P-value \\
\hline \multicolumn{9}{|l|}{ Age, years } \\
\hline$<65(\mathrm{n}=385)$ & $4.0 \pm 7.4$ & 0.150 & $72.7 \pm 31.9$ & 0.003 & $200.4 \pm 82.1$ & 0.158 & $|22.2 \pm 77|$. & 0.120 \\
\hline$\geq 65(n=425)$ & $4.9 \pm 10.6$ & & $65.9 \pm 32.9$ & & $208.1 \pm 73.9$ & & $131.5 \pm 75.9$ & \\
\hline \multicolumn{9}{|l|}{ Sex } \\
\hline Female $(n=185)$ & $5.4 \pm 11.9$ & 0.147 & $69.1 \pm 37.3$ & 0.984 & $199.80 \pm 75.56$ & 0.358 & $117.02 \pm 72.49$ & 0.061 \\
\hline Male $(n=625)$ & $4.2 \pm 8.3$ & & $69.1 \pm 31.2$ & & $205.82 \pm 78.7$ I & & $|30.43 \pm 77.6|$ & \\
\hline \multicolumn{9}{|l|}{ BMI } \\
\hline Underweight $(n=3)$ & $3.9 \pm 2.9$ & 0.311 & $70.4 \pm 42.9$ & 0.653 & $220.1 \pm 82.5$ & 0.172 & $201.9 \pm 65.3$ & 0.369 \\
\hline Normal $(n=116)$ & $5.9 \pm 13.7$ & & $72.6 \pm 31.2$ & & $204.8 \pm 80.9$ & & $135.1 \pm 74.2$ & \\
\hline Overweight $(n=365)$ & $4.1 \pm 9.3$ & & $68.7 \pm 35.5$ & & $198.1 \pm 79.8$ & & $126.2 \pm 79.7$ & \\
\hline Obesity $(n=326)$ & $4.4 \pm 6.7$ & & $68.3 \pm 29.6$ & & $211.2 \pm 74.6$ & & $125.1 \pm 73.7$ & \\
\hline \multicolumn{9}{|l|}{ Hypertonia arterialis } \\
\hline Yes $(n=6 \mid 6)$ & $4.9 \pm 9.8$ & 0.284 & $68.9 \pm 30.9$ & 0.855 & $203.4 \pm 76.5$ & 0.518 & $124.7 \pm 73.2$ & 0.138 \\
\hline No $(n=194)$ & $3.9 \pm 6.9$ & & $69.5 \pm 37.5$ & & $207.7 \pm 82.8$ & & $135.2 \pm 85.9$ & \\
\hline \multicolumn{9}{|l|}{ Diabetes mellitus } \\
\hline Yes $(n=276)$ & $4.2 \pm 7.5$ & 0.496 & $65.6 \pm 31.5$ & 0.030 & $214.4 \pm 78.8$ & 0.010 & $133.8 \pm 80.8$ & 0.108 \\
\hline No $(n=534)$ & $4.7 \pm 9.9$ & & $70.8 \pm 33.1$ & & $199.3 \pm 77.1$ & & $123.6 \pm 73.9$ & \\
\hline \multicolumn{9}{|l|}{ Renal failure } \\
\hline Yes $(n=35)$ & $3.9 \pm 6.5$ & 0.712 & $61.6 \pm 27.8$ & 0.165 & $209.9 \pm 82.8$ & 0.680 & $131.9 \pm 91.3$ & 0.730 \\
\hline No $(n=775)$ & $4.5 \pm 9.3$ & & $69.4 \pm 32.8$ & & $204.2 \pm 77.8$ & & $126.9 \pm 75.7$ & \\
\hline \multicolumn{9}{|l|}{ Myocardial infarction } \\
\hline Yes $(n=428)$ & $5.1 \pm 10.1$ & 0.051 & $70.2 \pm 35.9$ & 0.289 & $210.3 \pm 76.2$ & 0.024 & $131.3 \pm 76.9$ & 0.139 \\
\hline No $(n=382)$ & $3.8 \pm 8.1$ & & $67.8 \pm 28.6$ & & $197.9 \pm 79.5$ & & $122.3 \pm 75.8$ & \\
\hline
\end{tabular}

Notes: Data presented as mean \pm standard deviation. Data in bold indicates statistical significance. Abbreviations: BMI, body mass index; CRP, C-reactive protein.

Figure 1 shows the FVC and preoperative CRP level. The worse the FVC parameter, the higher the preoperative CRP level. Figure 2 shows significantly lower $\mathrm{FEV}_{1}$ values in patients with preoperative CRP levels exceeding $10 \mathrm{mg} / \mathrm{L}$.

We also examined correlations between the results of spirometry and CRP level before surgery, and on the second, fourth and sixth day after surgery (Table 3 ). There was a negative correlation between $\mathrm{FVC}$ and $\mathrm{FEV}_{1}$ parameters and all CRP values, which indicates the significant relationship

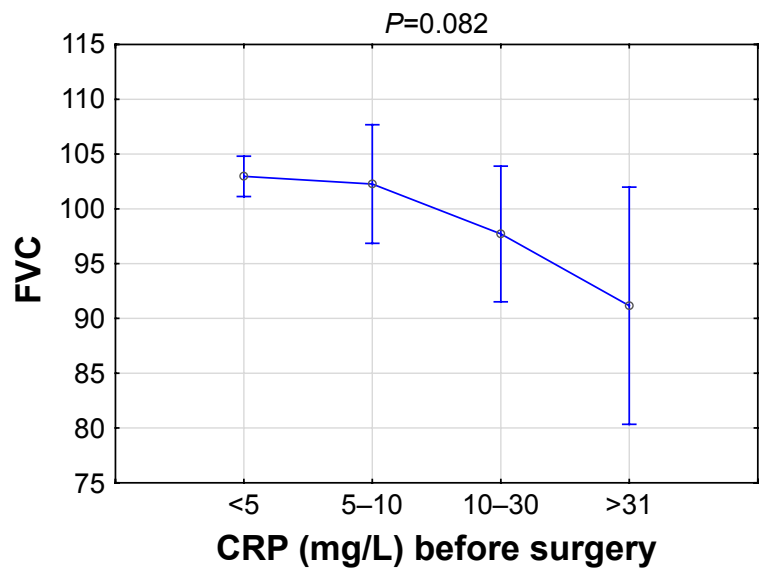

Figure I FVC and preoperative CRP.

Abbreviations: CRP, C-reactive protein; FVC, forced vital capacity. between the results of the spirometry and the inflammatory parameter. In the $\mathrm{FEV}_{1} / \mathrm{FVC}$ analysis, a significant negative correlation was only observed on the fourth day after surgery. In contrast, PEF was negatively correlated with CRP before surgery and on the fourth and sixth day after surgery.

\section{Discussion}

Unlike physical examinations and (to some extent) imaging studies, spirometry allows a quantitative evaluation of the respiratory system.

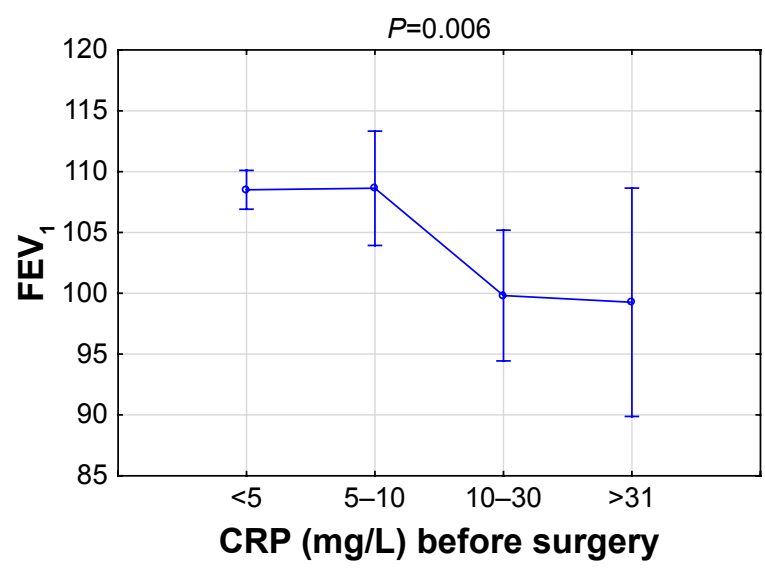

Figure 2 FEV and preoperative CRP.

Abbreviations: CRP, C-reactive protein; $\mathrm{FEV}_{1}$, forced expiratory volume in I s. 
Table 3 Correlation analysis according to spirometry parameters and preoperative and postoperative CRP

\begin{tabular}{|c|c|c|c|c|c|}
\hline \multirow{2}{*}{$\begin{array}{l}\text { Spirometry } \\
\text { parameters } \\
(n=8 \mid 0)\end{array}$} & \multicolumn{5}{|l|}{ CRP (mg/L) } \\
\hline & Admission & $\begin{array}{l}2 \text { days after } \\
\text { surgery }\end{array}$ & $\begin{array}{l}4 \text { days after } \\
\text { surgery }\end{array}$ & $\begin{array}{l}6 \text { days after } \\
\text { surgery }\end{array}$ & $\begin{array}{l}7 \text { days after } \\
\text { surgery }\end{array}$ \\
\hline \multirow[t]{2}{*}{ FVC (\%) } & -0.112 & -0.095 & -0.081 & -0.1314 & -0.1005 \\
\hline & $P=0.005$ & $P=0.017$ & $P=0.04 I$ & $P=0.001$ & $P=0.172$ \\
\hline \multirow[t]{2}{*}{$\mathrm{FEV}_{1}(\%)$} & -0.152 & -0.107 & -0.151 & -0.152 & -0.019 \\
\hline & $P<0.001$ & $P=0.007$ & $P<0.001$ & $P<0.001$ & $P=0.795$ \\
\hline \multirow[t]{2}{*}{$\mathrm{FEV}_{1} / \mathrm{FVC}(\%)$} & -0.013 & -0.018 & -0.105 & -0.037 & 0.073 \\
\hline & $P=0.737$ & $P=0.649$ & $P=0.008$ & $P=0.357$ & $P=0.320$ \\
\hline \multirow[t]{2}{*}{ PEF (\%) } & -0.151 & -0.002 & $-0.14 \mid$ & -0.079 & 0.027 \\
\hline & $P<0.001$ & $P=0.954$ & $P<0.001$ & $P=0.047$ & $P=0.716$ \\
\hline
\end{tabular}

Note: Data in bold indicates statistical significance.

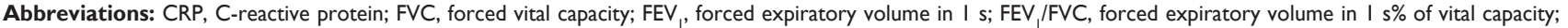
PEF, peak expiratory flow.

In our study, patients with restrictive breathing who qualified for CABG surgery had elevated CRP levels before and after surgery compared with patients with no respiratory dysfunctions. Hancox showed higher inflammatory response in people with restrictive breathing compared with those with obstructive disorders, in a screening study on healthy individuals who were approximately half the age of patients in our study group. ${ }^{15}$

We observed a negative correlation between the initial spirometric parameters $\mathrm{FVC}, \mathrm{FEV}_{1}$ and $\mathrm{FEV}_{1} / \mathrm{FVC}, \mathrm{PEF}$, and CRP levels before and after surgery. A study by Yende et al on the elderly showed a negative correlation between $\mathrm{FEV}_{1}$ and the systemic level of interleukin (IL)-6, which stimulates the production of CRP. ${ }^{26}$ Another study on healthy and nonsmoking individuals by Aronson et al also showed a reverse correlation between CRP and the respiratory capacity parameters. ${ }^{9}$ The negative correlation between FVC, FEV and CRP was stronger in men in a study by Ólafsdóttir et al. ${ }^{27}$ Hancox et al reported a correlation between respiratory distress and elevated CRP level. Increased values of CRP also correlated with low FVC. ${ }^{15}$

In our study, higher CRP level was observed in women with $\mathrm{FEV}_{1}$ below $80 \%$. This is contrary to the results of Rassmussen et al who reported higher CRP level in men, and Hancox et al who found no statistically significant differences between both the sexes. ${ }^{13,15}$

McAllister et al postulated that $\mathrm{FEV}_{1}$ is a predictor for a longer patient stay in the hospital and increased mortality after cardiac surgery. They emphasized that the spirometry parameter FEV 1 should be added to the current Euroscore operational risk assessment for availability, ease of use and low cost of spirometry testing. ${ }^{1,28}$

In patients following coronary artery bypass, those with obstructive pulmonary disease are at a higher risk of respiratory tract infection compared with those without this disorder. ${ }^{29}$ Grover et al report that a significant decrease in $\mathrm{FEV}_{1}$ (below 1.25 L) after CABG surgery was associated with increased postoperative mortality. ${ }^{30}$ A relationship between obstructive pulmonary disorders and postoperative complications has also been described. ${ }^{31}$ Patients after cardiac surgery have been reported to have a higher postoperative mortality when they suffered moderate-to-severe obstructive pulmonary disease. There was also a ten-times higher risk of death in these patients. ${ }^{32}$

In our study, the group was homogeneous and there was no relationship between respiratory disorders and mortality. The only observed relationship was found between the occurrence of obstructive disorders in the spirometry study and an elevated CRP level on the fourth postoperative day compared with patients with normal spirometry. Similar correlations were demonstrated between preoperative $\mathrm{FEV}_{1} / \mathrm{FVC}$ and CRP levels on the fourth day after surgery.

Our study has shown an increase in CRP in patients with an $\mathrm{FVC}$ below $80 \%$. There was also a significantly higher BMI in this group. This has been confirmed by post-hoc testing comparing patients with obstructive respiratory disorders and those without any respiratory problems. Many reports suggest that obesity results in decreased FVC. ${ }^{33,34}$ Leone et al show a decrease in spirometry parameters in patients with abdominal obesity, mainly in $\mathrm{FVC}$ and $\mathrm{FEV}_{1} \cdot{ }^{35}$ It is worth mentioning that out of many risk factors for ischemic heart disease, only a few are modifiable, one of them being a reduction in weight.

It is worth noting that the function of the respiratory system tested by means of spirometry allows an evaluation of the airflow through the lungs and also the strength of the skeletal muscles. ${ }^{36}$ The described spirometry parameters should be included in the preoperative risk assessment. Information about pulmonary dysfunction prior to surgery may improve the patient's respiratory system faster and more efficiently and may be important in preventing complications following coronary artery bypass surgery. 


\section{Conclusion}

In our study, the most common pulmonary disorders in the CABG patients were restrictive.

Education of patients with preoperative respiratory disorders should also include education on the benefits of adopting a pro-health lifestyle, weight reduction, monitoring glycemic levels, any of which could lead to a lower risk of respiratory complications in these patients after surgery.

Patients with abnormal spirometry results from restrictive respiratory disorders have an elevated level of generalized inflammatory response both before and after the isolated coronary artery bypass surgery. Therefore, this group of patients should be given special postoperative monitoring and, in particular, intensive respiratory rehabilitation immediately after surgery.

\section{Limitations}

Our study was limited by the number of patients with particular types of respiratory disorders. In order to obtain more representative results for the general population, the number of patients with obstructive ventilation should be increased in future research. Another significant limitation of this study was the difference in the number of women and men, which was due to the uneven number of patients qualified for CABG. In the future, spirometry should also be performed after CABG.

\section{Disclosure}

The authors report no conflicts of interest in this work.

\section{References}

1. McAllister DA, Wild SH, MacLay JD, et al. Forced expiratory volume in one second predicts length of stay and in-hospital mortality in patients undergoing cardiac surgery: a retrospective cohort study. PLoS One. 2013;8(5):e64565.

2. Ferreira GM, Haeffner MP, Barreto SS, Dall'Ago P. Incentive spirometry with expiratory positive airway pressure brings benefits after myocardial revascularization. Arq Bras Cardiol. 2010;94(2):230-235.

3. Branson RD. The scientific basis for postoperative respiratory care. Respir Care. 2013;58(11):1974-1984.

4. Narayanan ALT, Syed Hamid SRG, Supriyanto E. Evidence regarding patient compliance with incentive spirometry interventions after cardiac, thoracic and abdominal surgeries: a systematic literature review. Can J Respir Ther. 2016;52(1):17-26.

5. Hulzebos EH, Van Meeteren NL, De Bie RA, Dagnelie PC, Helders PJ. Prediction of postoperative pulmonary complications on the basis of preoperative risk factors in patients who had undergone coronary artery bypass graft surgery. Phys Ther. 2003;83(1):8-16.

6. Groeneveld AJ, Jansen EK, Verheij J. Mechanisms of pulmonary dysfunction after on-pump and off-pump cardiac surgery: a prospective cohort study. J Cardiothorac Surg. 2007;2(11):1-7.

7. Nashef SAM. Editorial comment: what to do with EuroSCORE in 2009? Eur J Cardiothorac Surg. 2009;36(5):805-806.

8. Cesario A, Ferri L, Galetta D, et al. Pre-operative pulmonary rehabilitation and surgery for lung cancer. Lung Cancer. 2007;57(1):118-119.

9. Aronson D, Roterman I, Yigla M, et al. Inverse association between pulmonary function and C-reactive protein in apparently healthy subjects. Am J Respir Crit Care Med. 2006;174(6):626-632.
10. Hancox RJ, Poulton R, Greene JM, et al. Systemic inflammation and lung function in young adults. Thorax. 2007;62(12):1064-1068.

11. Gläser S, Ittermann T, Koch B, et al. Airflow limitation, lung volumes and systemic inflammation in a general population. Eur Respir J. 2012; 39(1):29-37.

12. Thorleifsson SJ, Margretardottir OB, Gudmundsson G, et al. Chronic airflow obstruction and markers of systemic inflammation: results from the BOLD study in Iceland. Respir Med. 2009;103(10):1548-1553.

13. Rasmussen F, Mikkelsen D, Hancox RJ, et al. High-sensitive C-reactive protein is associated with reduced lung function in young adults. Eur Respir J. 2009;33(2):382-388.

14. Shaaban R, Kony S, Driss F, et al. Change in C-reactive protein levels and $\mathrm{FEV}_{1}$ decline: a longitudinal population-based study. Respir Med. 2006;100(12):2112-2120.

15. Hancox RJ, Gray AR, Sears MR, Poulton R. Systemic inflammation and lung function: A longitudinal analysis. Respir Med. 2016;111:54-59.

16. Kalhan R, Tran BT, Colangelo LA, et al. Systemic inflammation in young adults is associated with abnormal lung function in middle age. PLoS One. 2010;5(7):e11431.

17. Williams MJ, Williams SM, Milne BJ, Hancox RJ, Poulton R. Association between C-reactive protein, metabolic cardiovascular risk factors, obesity and oral contraceptive use in young adults. Int $J$ Obes Relat Metab Disord. 2004;28(8):998-1003.

18. Littleton SW. Impact of obesity on respiratory function. Respirology. 2012;17(1):43-49.

19. Kraft F, Schmidt C, Van Aken H, Zarbock A. Inflammatory response and extracorporeal circulation. Best Pract Res Clin Anaesthesiol. 2015;29(2):113-123.

20. Agusti A, Soriano JB. COPD as a systemic disease. COPD. 2008;5(2): 133-138.

21. Standardization of spirometry, 1994 update. American Thoracic Society. Am J Respir Crit Care Med. 1995;152(3):1107-1136.

22. American Thoracic Society. Single-breath carbon monoxide diffusing capacity (transfer factor). Recommendations for a standard technique-1995 update. Am J Respir Crit Care Med. 1995;152(6 Pt 1): 2185-2198.

23. MacIntyre N, Crapo RO, Viegi G, et al. Standardisation of the singlebreath determination of carbon monoxide uptake in the lung. Eur Respir J. 2005;26(4):720-735.

24. Miller MR, Hankinson J, Brusasco V, et al; ATS/ERS Task Force. Standardisation of spirometry. Eur Respir J. 2005;26(2):319-338.

25. Ford ES, Cunningham TJ, Mercado CI. Lung function and metabolic syndrome: findings of National Health and Nutrition Examination Survey 2007-2010. J Diabetes. 2014;6(6):603-613.

26. Yende S, Waterer GW, Tolley EA, et al. Inflammatory markers are associated with ventilatory limitation and muscle dysfunction in obstructive lung disease in well functioning elderly subjects. Thorax. 2006;61(1):10-16.

27. Ólafsdóttir IS, Gíslason T, Gudnason V, et al. CRP is associated with lung function decline in men but not women: a prospective study. Respir Med. 2013;107(1):91-97.

28. Lee DH, Buth KJ, Martin BJ, Yip AM, Hirsch GM. Frail patients are at increased risk for mortality and prolonged institutional care after cardiac surgery. Circulation. 2010;121(8):973-978.

29. Manganas H, Lacasse Y, Bourgeois S, Perron J, Dagenais F, Maltais F. Postoperative outcome after coronary artery bypass grafting in chronic obstructive pulmonary disease. Can Respir J. 2007;14(1):19-24.

30. Grover FL, Hammermeister KE, Burchfiel C. Initial report of the veterans administration preoperative risk assessment study for cardiac surgery. Ann Thorac Surg. 1990;50(1):12-26.

31. Kurki TS, Kataja M. Preoperative prediction of postoperative morbidity in coronary artery bypass grafting. Ann Thorac Surg. 1996;61(6): 1740-1745.

32. Adabag AS, WassifHS, Rice K, et al. Preoperative pulmonary function and mortality after cardiac surgery. Am Heart J. 2010;159(4):691-697.

33. Sorlí-Aguilar M, Martín-Luján F, Flores-Mateo G, et al. Adiposity markers and lung function in smokers: a cross-sectional study in a Mediterranean population. BMC Pulmonary Medicine. 2016;16(178):1-8. 
34. Vatrella A, Calabrese C, Mattiello A, et al. Abdominal adiposity is an early marker of pulmonary function impairment: findings from a Mediterranean Italian female cohort. Nutr Metab Cardiovasc Dis. 2016; 26(7):643-648.

35. Leone N, Courbon D, Thoomas F, et al. Lung function impairment and metobalic syndrome the critical role of abdominal obesity. Am J Respir Crit Care Med. 2009;179(6):509-516.
36. Wróblewska I, Oleśniewicz P, Kurpas D, Sołtysik M, Błaszczuk J. Analysis of spirometry results in hospitalized patients aged over 65 years. Clin Interv Aging. 2015;10:1071-1076.

\section{Publish your work in this journal}

Clinical Interventions in Aging is an international, peer-reviewed journal focusing on evidence-based reports on the value or lack thereof of treatments intended to prevent or delay the onset of maladaptive correlates of aging in human beings. This journal is indexed on PubMed Central, MedLine,

\section{Dovepress}

CAS, Scopus and the Elsevier Bibliographic databases. The manuscript management system is completely online and includes a very quick and fair peer-review system, which is all easy to use. Visit http://www.dovepress. $\mathrm{com} /$ testimonials.php to read real quotes from published authors. 